\title{
Effect of size factor on the Ruddlesden-Popper single-slab compounds structure features
}

\author{
Yuriy A. Titov ${ }^{a^{*}}$, Nadegda N. Belyavina ${ }^{\mathrm{b}}$, Mikola S. Slobodyanik ${ }^{\mathrm{a}}$, Olesya I. Nakonechna ${ }^{\mathrm{b}}$, \\ Nataliia Y. Strutynska ${ }^{a}$ \\ a Department of Chemistry, Taras Shevchenko National University of Kyiv, \\ Volodymyrska Street, 64/13, Kyiv 01601, Ukraine \\ ${ }^{\mathrm{b}}$ Department of Physics, Taras Shevchenko National University of Kyiv, \\ Acad. Glushkova avenue, 4-b, Kyiv 03022, Ukraine \\ tit@univ.kiev.ua
}

Keywords: Ruddlesden-Popper compound, solid solution, X-ray powder diffraction method, slab perovskite-like structure.

Character of influence of the strontium atoms replacement by smaller atoms of calcium on structure features of the Ruddlesden-Popper $(\mathrm{Sr}, \mathrm{Ca}) \mathrm{LaScO}_{4}\left(\mathrm{~A}_{2} \mathrm{BO}_{4}\right)$ single-slab compound is established. Structure of phase with a maximum degree of replacement has determined by the Rietveld method. It is shown that such type of substitution increases a degree of $\mathrm{AO}_{9}$ interblock polyhedra deformation, mutual inclination of the $\mathrm{BO}_{6}$ octahedra and a decrease of $\mathrm{A}$ - $\mathrm{O}$ interblock bond. Presence of structure changes is the precondition for regulation of structural-dependent features of the materials on the base of scandates alkaline-earth and rare earth metals.

\section{Introduction}

The Ruddlesden-Popper oxide compounds of the $\mathrm{A}_{n+1} \mathrm{~B}_{\mathrm{n}} \mathrm{O}_{3 \mathrm{n}+1}$ family $(\mathrm{A}=\mathrm{Ba}$, Sr, Ca, La-Yb; B = Ti, Zr, Hf, Sn, Zr, Mn,W, V, $\mathrm{Re}, \mathrm{Al}, \mathrm{Ga}, \mathrm{Cr}, \mathrm{Fe}, \mathrm{Co}, \mathrm{Ni}, \mathrm{Sc}, \mathrm{In}$; $(n$ is a number of slabs of the $\mathrm{BO}_{6}$ octahedra in the perovskite-like block, which is ranged from 1 to 3) with a slab perovskite-like structure (SPS) are a subject of interest in recent times because of their electrophysical, catalytic, ion exchange and optical characteristics [1-7].

The necessity of solving the problem of their task-oriented regulation creates a role of research on the synthesis of new compounds of this family and isomorphically substituted phases on the basis of known $\mathrm{A}_{n+1} \mathrm{~B}_{n} \mathrm{O}_{3 n+1}$ - type compounds with SPS.

Isomorphic substitution of atoms in different crystallographic positions of their structure is one of the ways of regulation characteristics of the oxide and oxide-based compounds and materials. At the same time sizes of substitutional atom are certainly one of the most influential factors, which determines the borders of isomorphic substitution. 
The effect of geometric factor on the structure and existence intervals of solid solutions on the base of $\mathrm{A}_{n+1} \mathrm{~B}_{n} \mathrm{O}_{3 n+1}$ compounds with SPS could be determined by analyzing the structure of the SPS phases of $\left(\mathrm{A}, \mathrm{A}^{\mathrm{I}}\right)_{\mathrm{n}+1}\left(\mathrm{~B}, \mathrm{~B}^{\mathrm{I}}\right)_{\mathrm{n}} \mathrm{O}_{3 \mathrm{n}+1}$ type. In such phases, the $\mathrm{A}$ and $\mathrm{A}^{\mathrm{I}}$ atoms as well as $\mathrm{B}$ and $\mathrm{B}^{\mathrm{I}}$ differ only by their size, and are completely analogous to the rest of their characteristics. But, until now such researches were carried out only for indium- and aluminum-content representatives of the family of $\mathrm{A}_{n+1} \mathrm{~B}_{\mathrm{n}} \mathrm{O}_{3 n+1}$ - type compound with SPS $[8,9]$.

The purpose of the present work is to study the influence of isovalent substitution of $\mathrm{Sr}$ by smaller $\mathrm{Ca}$ atoms in the $\mathrm{SrLaScO}_{4}$ singleslab scandate by the SPS structure of $\mathrm{Sr}_{1-\mathrm{x}} \mathrm{Ca}_{\mathrm{x}} \mathrm{LaScO}_{4}$ phases.

\section{Experimental part}

Synthesis of the $\mathrm{Sr}_{1-\mathrm{x}} \mathrm{Ca}_{\mathrm{x}} \mathrm{LaScO}_{4}$ polycrystalline scandates was carried out by co - crystallization (evaporation at intensive mixing) of the mixture of strontium, calcium, lanthanum and scandium nitrates aqueous solution (ratio is equal to $\mathrm{Sr}: \mathrm{Ca}: \mathrm{La}: \mathrm{Sc}=$ $1-\mathrm{x}: \mathrm{x}: 1: 1)$ with further thermal treatment of the product obtained with a gas-jet to remove the main part of the nitrogen oxides. Then the powder obtained was grinded, pressed as tablets and heat treated at $1570 \mathrm{~K}$ to achieve the constant phase composition. $\operatorname{Sr}\left(\mathrm{NO}_{3}\right)_{2}$, $\mathrm{Ca}\left(\mathrm{NO}_{3}\right)_{2}, \mathrm{La}\left(\mathrm{NO}_{3}\right)_{3}, \mathrm{Sc}\left(\mathrm{NO}_{3}\right)_{3}$ (reagents grade) were used as the source materials.
The X-ray powder diffraction data of samples were collected with Shimadzu XRD-6000 diffractometer $(\mathrm{Cu} \mathrm{K} \alpha$ radiation). The diffractometer was equipped graphite arc before counter. The scanning method parameters are the following: observation range $2 \theta=20-85^{\circ}$, step scan is $0.02^{\circ}$, counting time per step is $5 \mathrm{~s}$. Since the incident beam is only filtered, the diffraction peaks contain $\mathrm{Cu} \mathrm{K}_{1}$ and $\mathrm{Cu} \mathrm{K \alpha} \alpha_{2}$ constituents. The peak positions and integrated intensities of the observed reflections were determined using full profile analyses. After removal the $\mathrm{K} \alpha_{2}$ component the profiles were fitted using Lorentz functions.

Automatic indexing of the diffraction pattern was carried out with the program based on the Ito procedure. Unit cell refinement was carried out with the least-squares refinement program using corrected powder diffraction data. The crystal structure determination was performed using an original software program package with a special data bank for structure types of inorganic compounds (more than 9000 information units) and the X-ray diffraction images of these structure types. The testing of the structure models and the structure parameter refinement were carried out with original software [10].

\section{Results and discussion}

At the first stage of experiment we have determined the concentration range (value $\mathrm{x}$ ) existence of the phases with SPS in the $\mathrm{Sr}_{1-\mathrm{x}} \mathrm{Ca}_{\mathrm{x}} \mathrm{LaScO}_{4}$ system. X-ray diffraction study 
of calcinating at $1570 \mathrm{~K}$ samples of bulk $\mathrm{Sr}_{1-\mathrm{x}} \mathrm{Ca}_{\mathrm{x}} \mathrm{LaScO}_{4}$ composition has revealed that samples with $x=0.1,0.2$ and 0.3 keep slab perovskite-like structure. Samples with $x=0.4$ and 0.5 contain impurity phases (among phase with SPS) while the phase with the structure of three-dimensional perovskite is the main one for nonmonophases samples with $x \geq 0.6$.

The indexing of the X-ray powder diffraction pattern of the $\mathrm{Sr}_{1-\mathrm{x}} \mathrm{Ca}_{\mathrm{x}} \mathrm{LaScO}_{4}$ $(0 \leq \mathrm{x} \leq 0.3)$ has revealed the orthorhombic symmetry of the heat treated samples. The observed systematic extinctions (present X-ray reflections: $h k l$ with $k+1=2 n, 0 k l$ with $k, l=2 n$, $h 0 l$ with $l=2 n, h k 0$ with $h, k=2 n, h 00,0 k 0,001$ with $h, k, l=2 n$ ) indicate that their crystal structure belongs to centrosymmetrical Abma space group.

Based on the results obtained we have determined the SPS for $\mathrm{Sr}_{0.7} \mathrm{Ca}_{0.3} \mathrm{LaScO}_{4}$ phase with ultimate substitution degree of $\mathrm{Sr}$ atoms $(x)$ equal to 0.3 to solve the task assigned.

The atomic coordinates in $\mathrm{SrLaScO}_{4}$ (sp. gr. Abma) [3,11] have been used for the construction of initial structure model of $\mathrm{Sr}_{0.7} \mathrm{Ca}_{0.3} \mathrm{LaScO}_{4}$. The comparison of the observed and calculated intensities shows a good agreement for this structure model. The results of the refinement procedure and diffraction data are summarized in Tables 1, 2, and are shown in Figures 1 - 3. The composition of the $\mathrm{Sr}_{1-\mathrm{x}} \mathrm{Ca}_{\mathrm{x}} \mathrm{LaScO}_{4}$ phase that was specified while accounting the structure (10 at. \% Sr,
$4.3 \% \mathrm{Ca}, 14.3 \% \mathrm{La}, 14.3 \% \mathrm{Sc}, 57.1 \% \mathrm{O})$, corresponds to the experimentally specified one within the accuracy of measurement.

Table 1. Crystal data for $\mathrm{Sr}_{0,7} \mathrm{Ca}_{0,3} \mathrm{LaScO}_{4}$ phase

\begin{tabular}{|c|c|c|c|c|c|}
\hline Site & Atom & $\begin{array}{l}\text { Occu- } \\
\text { pancy }\end{array}$ & $\mathrm{X}$ & Y & Z \\
\hline \multirow{3}{*}{$8 \mathrm{f}$} & $\mathrm{Sr}$ & 0.35 & \multirow{3}{*}{$0.0115(1)$} & \multirow{3}{*}{0} & \multirow{3}{*}{$0.3530(2)$} \\
\hline & $\mathrm{Ca}$ & 0.15 & & & \\
\hline & $\mathrm{La}$ & 0.5 & & & \\
\hline $4 a$ & $\mathrm{Sc}$ & 1 & 0 & 0 & 0 \\
\hline $8 \mathrm{e}$ & $\mathrm{O} 1$ & 1 & 0.25 & 0,25 & 0.049(1) \\
\hline $8 \mathrm{f}$ & $\mathrm{O} 2$ & 1 & $0.493(2)$ & 0 & $0.329(1)$ \\
\hline \multicolumn{3}{|c|}{ Space group } & \multicolumn{3}{|c|}{ Abma (6402) } \\
\hline \multirow{3}{*}{\multicolumn{3}{|c|}{$\begin{array}{c}\text { Lattice } \\
\text { parameters, } \\
\text { nm }\end{array}$}} & \multirow{3}{*}{\multicolumn{3}{|c|}{$\begin{array}{l}\mathrm{a}=0.57814(9) \\
\mathrm{b}=0.57284(9) \\
\mathrm{c}=1.2389(3)\end{array}$}} \\
\hline & & & & & \\
\hline & & & & & \\
\hline \multicolumn{3}{|c|}{$\begin{array}{l}\text { Independent } \\
\text { reflections }\end{array}$} & \multicolumn{3}{|c|}{50} \\
\hline \multicolumn{3}{|c|}{$\begin{array}{l}\text { Total isotropic } \\
\text { factor } B, \mathrm{~nm}^{2}\end{array}$} & \multicolumn{3}{|c|}{$0.1(1) \cdot 10^{-2}$} \\
\hline \multirow{2}{*}{\multicolumn{3}{|c|}{$\begin{array}{c}\text { Texture } \\
\text { parameters }\end{array}$}} & \multirow{2}{*}{\multicolumn{3}{|c|}{$\begin{array}{c}0.84(3) \\
\text { texture axis }[001]\end{array}$}} \\
\hline & & & & & \\
\hline \multicolumn{3}{|c|}{ Reliability factor $R_{w}$} & \multicolumn{3}{|c|}{0.063} \\
\hline
\end{tabular}

$\mathrm{Sr}_{0.7} \mathrm{Ca}_{0.3} \mathrm{LaScO}_{4}$ SPS is formed by twodimensional (infinite in the direction of $X$ and $Y$ axes) perovskite-like blocks, each of them consists of one slab of the $\mathrm{ScO}_{6}$ octahedra, which are jointed by the vertices only. The blocks are shifted with respect to one another along the diagonal of $X Y$ plane by a half of perovskite cube edge and are subsequently alternated along the $Z$-axis (Fig. 2). 
Table 2. Selected interatomic distances $(d)$, degree of distortion $(\Delta)^{1}$ of $M e \mathrm{O}_{\mathrm{n}}$ polyhedra and corner

$\mathrm{Sc}-\mathrm{O} 1-\mathrm{Sc}$ of neighbouring octahedrons $\mathrm{ScO}_{6}$ in the crystal structure of $\mathrm{Sr}_{0.7} \mathrm{Ca}_{0.3} \mathrm{LaScO}_{4}$

\begin{tabular}{|c|c|c|c|}
\hline Distances & $\mathrm{d}, \mathrm{nm}$ & Distances & $\mathrm{d}, \mathrm{nm}$ \\
\hline$(\mathrm{Sr}, \mathrm{Ca}, \mathrm{La})-\mathrm{O} 2$ & $0.226(1)^{2}$ & $\mathrm{Sc}-4 \mathrm{O} 1$ & $0.212(1)$ \\
\hline$-2 \mathrm{O} 1$ & $0.241(1)$ & $-2 \mathrm{O} 2$ & $0.212(2)$ \\
\hline$-\mathrm{O} 2$ & $0.280(2)$ & \multirow{3}{*}{$\begin{array}{c}\text { Average } \\
\text { distance } \\
\mathrm{Sc}-\mathrm{O}\end{array}$} & \multirow{3}{*}{0.212} \\
\hline$-2 \mathrm{O} 2$ & $0.288(2)$ & & \\
\hline$-\mathrm{O} 2$ & $0.301(2)$ & & \\
\hline$-2 \mathrm{O} 1$ & $0.314(2)$ & $\Delta \mathrm{ScO}_{6}$ & 0 \\
\hline $\begin{array}{c}\text { Average } \\
\text { distance } \\
(\mathrm{Sr}, \mathrm{Ca}, \mathrm{La})-\mathrm{O}\end{array}$ & 0.277 & $\begin{array}{c}\text { Corner } \\
\text { Sc-Ol- } \\
\text { Sc, }{ }^{0}\end{array}$ & 147 \\
\hline$\Delta(\mathrm{Sr}, \mathrm{Ca}, \mathrm{La}) \mathrm{O}_{9}$ & $127 \cdot 10^{-4}$ & & \\
\hline
\end{tabular}

${ }^{1}$ The degrees of distortion of the $\mathrm{MeO}_{n}$ polyhedra were calculated as $\Delta=1 / n \sum\left[\left(R_{i}-\bar{R}\right) / \bar{R}\right]^{2}$ (where $R_{i}$ is the Me - $\mathrm{O}$ distance, $\bar{R}$ is the $\mathrm{Me}-\mathrm{O}$ average distance, $n$ is the coordination number for $\mathrm{Me}$ ) [12]

${ }^{2}$ Interblock distance (O2 atom located in the neighbour perovskite-like block).

There is no direct connection between $\mathrm{ScO}_{6}$ octahedra, which are placed in neighbouring perovskite-like blocks. The blocks are separated by slab of $(\mathrm{Sr}, \mathrm{Ca}, \mathrm{La}) \mathrm{O}_{9}$ polyhedra and linked through $-\mathrm{O}-(\mathrm{Sr}, \mathrm{Ca}, \mathrm{La})-\mathrm{O}-$ interblock bonds.

The necessity of $-\mathrm{O}-(\mathrm{Sr}, \mathrm{Ca}, \mathrm{La})-\mathrm{O}-$ bond formation to link the neighbouring perovskite-like blocks causes the $(\mathrm{Sr}, \mathrm{Ca}, \mathrm{La})$ atoms to be displaced from the cubooctahedral type holes towards the boundary of the

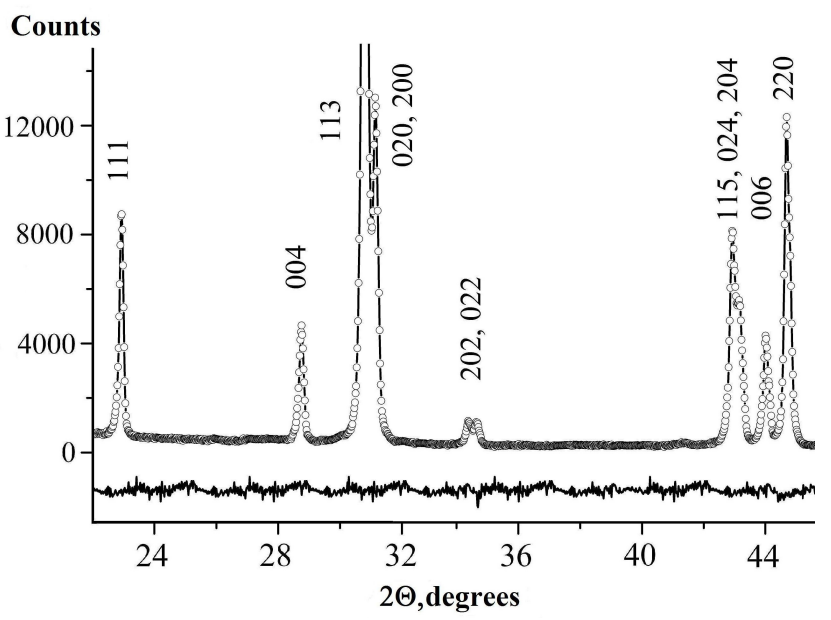

Figure 1. The experimental (points) and calculated (solid line) diffraction patterns for $\mathrm{Sr}_{0.7} \mathrm{Ca}_{0.3} \mathrm{LaScO}_{4}$ (sp. gr. Abma); their difference curve is shown below.

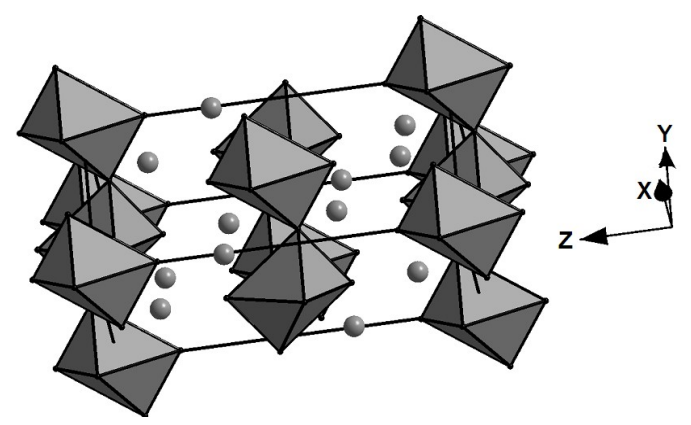

Figure 2. Crystal structure of the $\mathrm{Sr}_{0.7} \mathrm{Ca}_{0.3} \mathrm{LaScO}_{4}$ phase as an arrangement of the $\mathrm{ScO}_{6}$ octahedra and $\mathrm{Sr}, \mathrm{Ca}, \mathrm{La}$ atoms (circles).

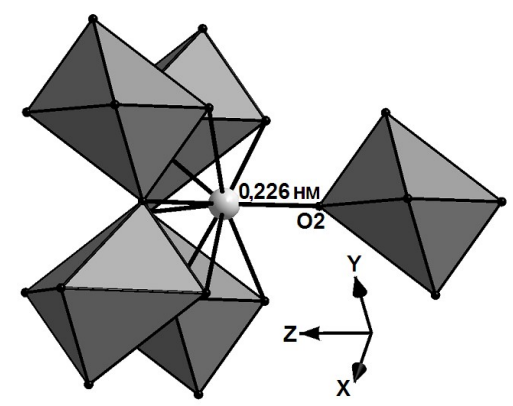

Figure 3. Interblock boundary construction for the $\mathrm{Sr}_{0.7} \mathrm{Ca}_{0.3} \mathrm{LaScO}_{4}(\mathrm{Sr}, \mathrm{Ca}$, La atoms - grey circle).

perovskite-like block (site 8c). Therefore, their coordination number occurs to be less than 12 . The (Sr,Ca,La) atoms is surrounded by 9 oxygen atoms (4O1 and $4 \mathrm{O} 2$ in the same block and $1 \mathrm{O} 2$ in the neighbouring block) (Fig. 3). 
The length of this interblock bond is the smallest in ( $\mathrm{Sr}, \mathrm{Ca}, \mathrm{La}) \mathrm{O}_{9}$ polyhedra $(0.226 \mathrm{~nm})$ (Table 2).

The comparison of the structure data for $\mathrm{Sr}_{0.7} \mathrm{Ca}_{0.3} \mathrm{LaScO}_{4}$ phase with maximum possible degree of the $\mathrm{Sr}$ atoms substitution and the known similar (by the composition) $\mathrm{SrLaScO}_{4}$ single-slab compound $[3,11]$ has revealed that occupation of $A$-position of the $\mathrm{SrLaScO}_{4}$ SPS by smaller $\mathrm{Ca}$ atoms leads to following changes:

- to essential reduction of the - O - (Sr,Ca,La) - O2 - interblock bond length (from $0.236-0.238 \mathrm{~nm}$ to $0.226 \mathrm{~nm}$ );

- to increase a of deformation degree of ( $\mathrm{Sr}, \mathrm{Ca}, \mathrm{La}) \mathrm{O}_{9}$ polyhedra (from $(78-98) \cdot 10^{-4}$ to 127) $\left.10^{-4}\right)$;

- to reduction the angle value of $\mathrm{Sc}-\mathrm{O} 1-\mathrm{Sc}$ bonds (from $169-170^{\circ}$ to $147^{\circ}$ ) that denotes the neighbouring $\mathrm{ScO}_{6}$ octahedra inclination degree increase.

Reduction in distance between perovskite-like slab of connected by the $\mathrm{ScO}_{6}$ octahedra vertices (which take place at increase of $\mathrm{Ca}$ atoms content) approaches a construction of $\mathrm{Sr}_{1-\mathrm{x}} \mathrm{Ca}_{\mathrm{x}} \mathrm{LaScO}_{4}$ SPS to thermodynamically stable perovskite structure. Exceeding of isovalent substitution boundary results eventually in occurrence of the phase with perovskite structure. At the same time, an increase both of the $(\mathrm{Sr}, \mathrm{Ca}, \mathrm{La}) \mathrm{O}_{9}$ polyhedra deformation degree and inclination degree of neighbouring $\mathrm{ScO}_{6}$ octahedra results in a rise of stress in the interblock space of $\mathrm{Sr}_{1-\mathrm{x}} \mathrm{Ca}_{\mathrm{x}} \mathrm{LaScO}_{4}$
SPS phases. In a whole, cumulative effect of the above-mentioned factors destabilizes SPS, limits the area of phases with SPS in $\mathrm{Sr}_{1-\mathrm{x}} \mathrm{Ca}_{\mathrm{x}} \mathrm{LaScO}_{4}$ system and causes the absence of $\mathrm{CaLaScO}_{4}$ compound with SPS.

It is necessary to note that the increase of the $(\mathrm{Sr}, \mathrm{Ln}) \mathrm{O}_{9}$ interblock polyhedra deformation degree also takes place the for single-slab $\mathrm{SrLnScO}_{4}$ scandates $(\mathrm{Ln}=\mathrm{La}-\mathrm{Sm})$ at a reduction of the size of Ln atom [11] and also is one of the main reasons of SPS destruction in this series compound.

\section{Conclusions}

Thus, in the present work the existence area of phases with SPS in the $\mathrm{Sr}_{1-\mathrm{x}} \mathrm{Ca}_{\mathrm{x}} \mathrm{LaScO}_{4}$ system is established and SPS constitutions of $\mathrm{Sr}_{0.7} \mathrm{Ca}_{0.3} \mathrm{LaScO}_{4}$ phase are determined. Analysis of structure data obtained has revealed the basic regularities of size effect of atoms in A-position of $\mathrm{SrLaScO}_{4}$ scandates on structure of singleslab $\mathrm{Sr}_{0.7} \mathrm{Ca}_{0.3} \mathrm{LaScO}_{4}$ phase and the factors that limit an existence range of $\mathrm{Sr}_{1-\mathrm{x}} \mathrm{Ca}_{\mathrm{x}} \mathrm{LaScO}_{4}$ phases with SPS. The results obtained could be used for regulation the structure-dependent properties of the $\mathrm{SrLaScO}_{4}$ based materials through isovalent atoms substitution in SPS.

\section{References}

[1] Alexandrov KC, Beznosikov BV, Perovskites. Present and future. Novosibirsk: SO RAN Publishers; 2004, pp.105-138.

[2] Kim IS, Nakamura T, Itoh M. Humidity sensing effects of the layered oxides $\mathrm{SrO} \cdot\left(\mathrm{LaScO}_{3}\right)_{\mathrm{n}}(\mathrm{n}=$ 1,2, $\infty)$. J. Ceram. Soc. Jap. 1993;101(7):800-803.

[3] Kim IS, Kawaji H, Itoh M, Nakamura T. Structural and dielectric studies on the new series of 
layered compounds, strontium lanthanum scandium oxides. Mat. Res. Bull. 1992;27(10):1193-1203.

[4] Schaak RE, Mallouk TE. Perovskites by design: a toolbox of solid-state reactions. Chem. Mater. 2002;14(4):1455-1471.

[5] Titov Y, Nedilko SG, Chornii V, Scherbatskii V, Belyavina N, Markiv V, Polubinskii V. Crystal structure and luminescence of layered perovskites $\mathrm{Sr}_{3} \mathrm{LnInSnO}_{8}$. Sol. St. Phenomena 2015; 230:67-72.

[6] Kato S, Ogasawara M, Sugai M, Nakata S. Synthesis and oxide ion conductivity of new layered perovskite $\mathrm{La}_{1-\mathrm{x}} \mathrm{Sr}_{1+\mathrm{x}} \mathrm{InO}_{4-\mathrm{d}}$. Sol. St. ionics 2002;149(12):53-57.

[7] Ueda K, Yamashita T, Nakayashiki K, Goto K, Maeda T, Furui K, Ozaki K, Nakachi Y, Nakamura S, Fujisawa M, Miyazaki T. Green, orange, and magenta luminescence in strontium stannates with perovskiterelated structures. Jap. J. Appl. Phys. 2006;45(9A):69816983.

[8] Titov YO, Belyavina NM, Slobodyanik MS, Babaryk AA, Timoschenko MV. Influence of composition on organization of layered perovskite-like structure of indates $\mathrm{A}^{\mathrm{II}} \mathrm{LaInO}_{4}$. Dopov. Nats. Akad. Nauk Ukr. 2017;4:70-75.

[9] Zvereva I, Smirnov Y, Choisnet J. Prominent part of calcium ordering in the formation and stability of the intergrowth type solid solution $\mathrm{La}_{2} \mathrm{Sr}_{1-\mathrm{x}} \mathrm{Ca}_{\mathrm{x}} \mathrm{Al}_{2} \mathrm{O}_{7}$. Internat. J. Inorg. Mater. 2001;3:95-100.

[10] Dashevskyi M, Boshko O, Nakonechna O, Belyavina N. Phase Transformations in Equiatomic $\mathrm{Y}-\mathrm{Cu}$ Powder Mixture at Mechanical Milling. Metallofiz. Noveishie Tekhnol. 2017;39(4):541-552.

[11] Patel R, Simon C, Weller MT. $\mathrm{LnSrScO}_{4}$ $(\mathrm{Ln}=\mathrm{La}, \mathrm{Ce}, \mathrm{Pr}, \mathrm{Nd}$ and $\mathrm{Sm})$ systems and structure correlations for $\mathrm{A}_{2} \mathrm{BO}_{4}\left(\mathrm{~K}_{2} \mathrm{NiF}_{4}\right)$ structure types. J. Sol. St. Chem. 2007;180:349-359.

[12] Shannon RD. Revised effective ionic radii and systematic studies of interatomic distances in halides and chalcogenides. Acta Crystallogr. 1976:A32: 751-767. 